\title{
USE OF SUPRATHEL IN SURGICAL, NON-SURGICAL AND ENZIMATICALLY DEBRIDED BURNS
}

\author{
Elena García-Vilariño, Enrique Salmerón González, Eloy Condiño Brito, Alberto Ruiz Cases, M. Dolores Pérez del Caz
} Unidad de Quemados. Hospital Universitari i Politècnic La Fe

\section{OBJECTIVE}

We evaluated the use of Suprathel ${ }^{\circledR}$, a synthetic copolymer membrane from polylactids that provides a temporary wound coverage in burn patients

\section{METHODS}

From April 2013 to May 2017, 29 patients with mid-dermal or deepdermal burns a were treated with Suprathel ${ }^{\circledR}$ and evaluated retrospectively.

Suprathel ${ }^{\circledR}$ was applied:

- After Nexobrid ${ }^{\circledR}$

- After hydro-debridement with Versajet ${ }^{\circledR}$

- On donor sites

- On mid-dermal non surgical burns.

The outer dressings were changed every 2-3 days and the evolution was closely evaluated.

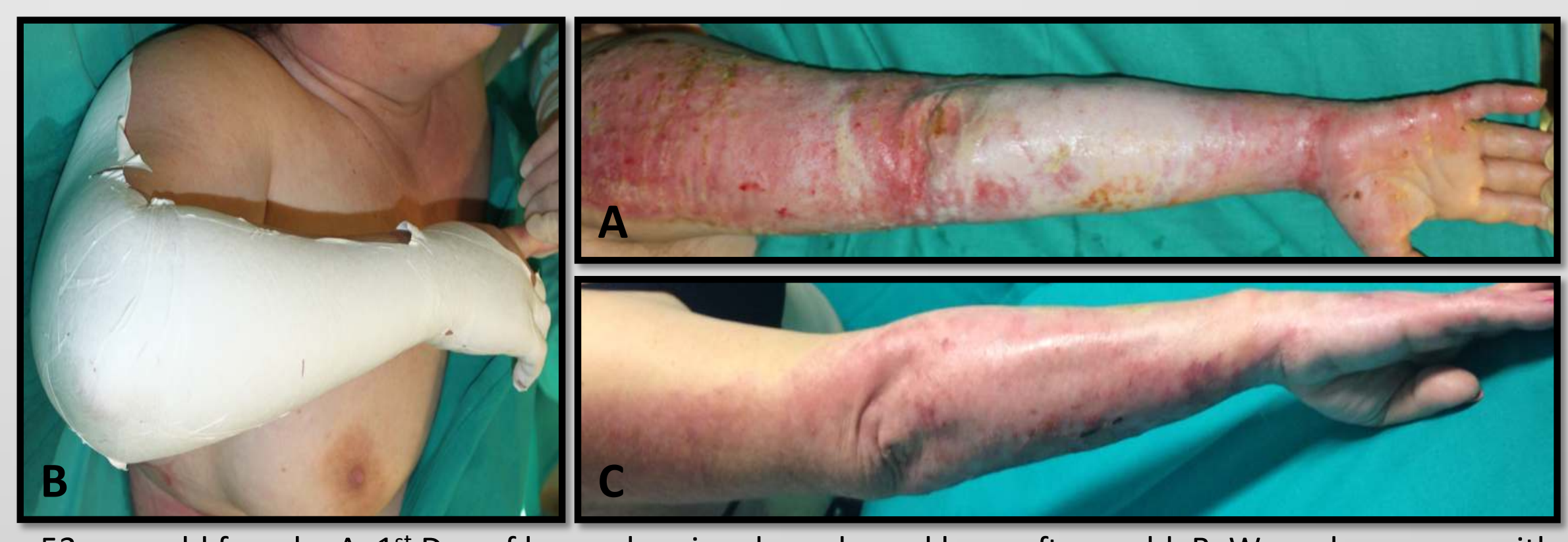

53 year-old female. A. $1^{\text {st }}$ Day of burn, showing deep dermal burn after scald. B. Wound coverage with Suprathel ${ }^{\circledR}$ atemergencycare. C. Complete reepithelization after a following period of 30 days

\section{RESULTS}

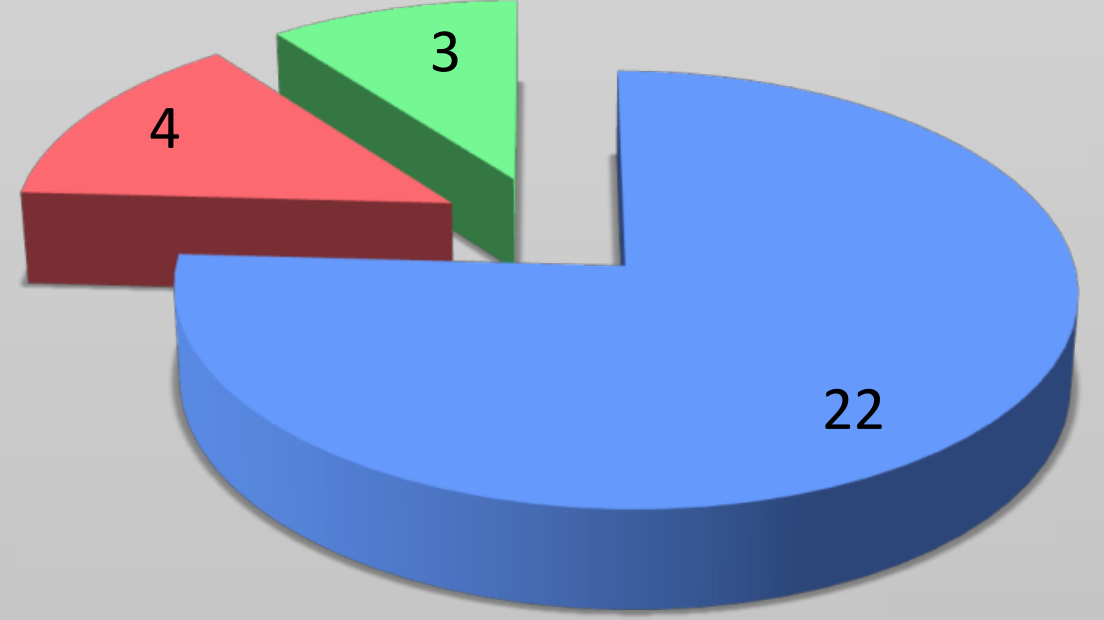

No Complications

STSG

Infection + STSG
Debrided with Versajet ${ }^{\circledR}$

Debrided with Nexobrid ${ }^{\circledR}$

Donor sites

Mid-dermal burns

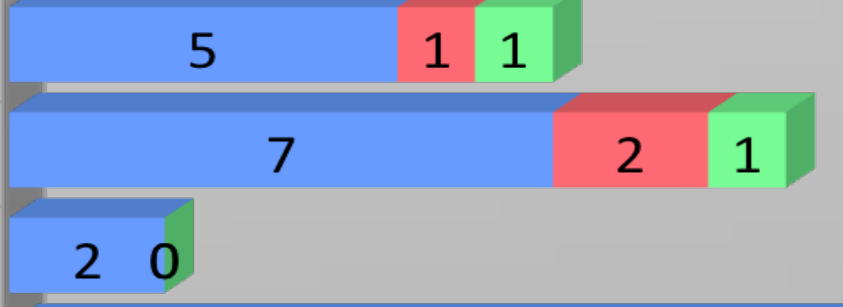

15
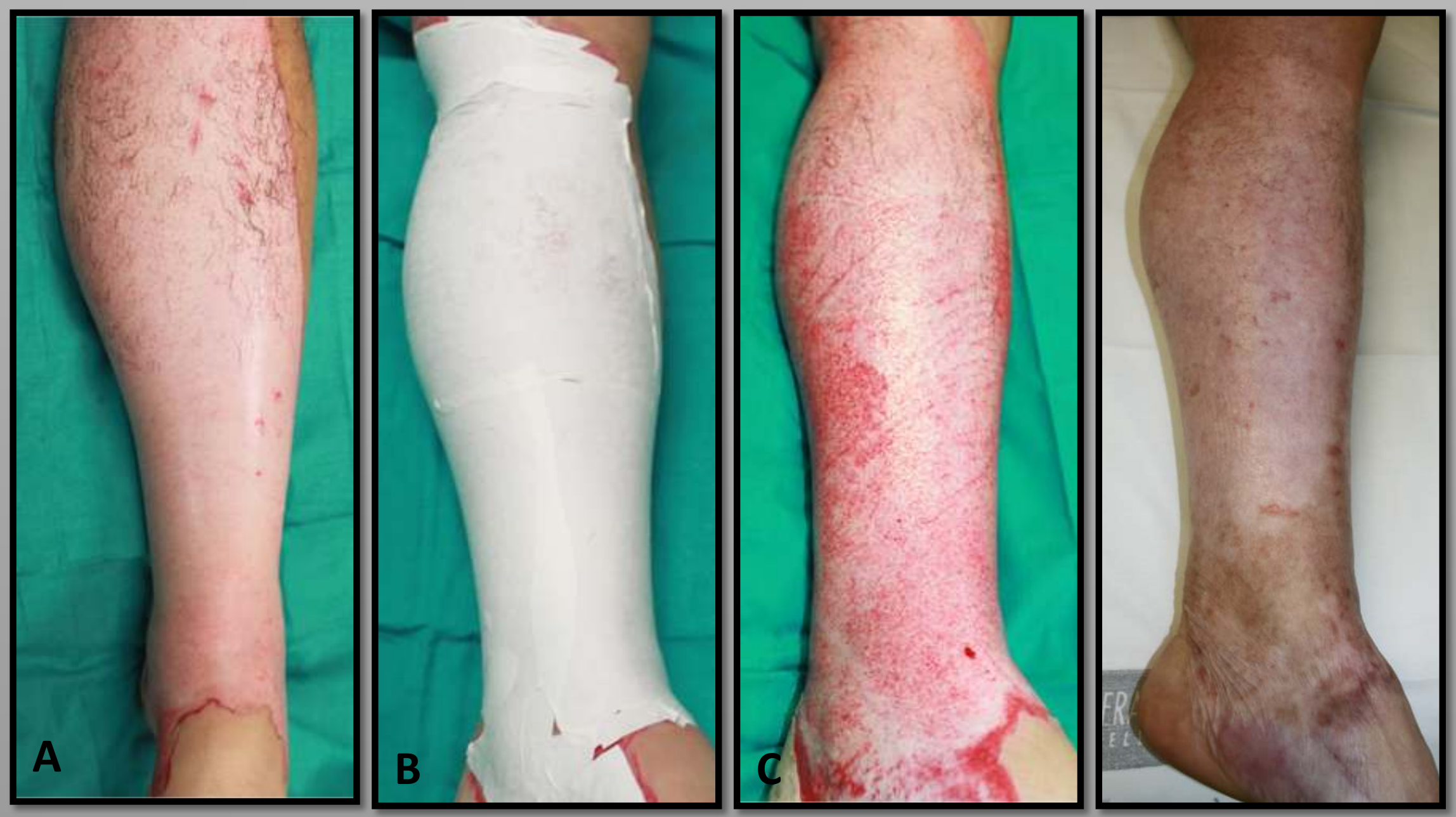

48 year-old male. A. $1^{\text {st }}$ Day after fire burn. B. $3^{\text {rd Day }}$ of burn after Nexobrid ${ }^{\circledast}$.C. $3^{\text {rd }}$ day Suprathe ${ }^{\circledR}$ placement. D. 40 days after deep-dermal burn

\section{CONCLUSION}

Suprathel has proved to be a useful dressing in certain burn cases. Due to the reduction in cure frequency and wound manipulation a reduction of pain, sedation procedures, fasting periods and anesthetic medication are achieved. 